Article

\title{
Can Social Networks Make Us More Sensitive to Social Discrimination? E-Contact, Identity Processes and Perception of Online Sexual Discrimination in a Sample of Facebook Users
}

\author{
Tiziana Mancini * (1) and Chiara Imperato \\ Department of Humanities, Social Sciences and Cultural Industries, University of Parma, 43121 Parma, Italy; \\ chiara.imperato@unipr.it \\ * Correspondence: tiziana.mancini@unipr.it
}

Received: 19 March 2020; Accepted: 7 April 2020; Published: 9 April 2020

check for updates

\begin{abstract}
In recent years psychosocial studies have given a growing attention to online intergroup contact in reducing prejudice. Nevertheless, there is still a lack of evidence on processes that could mediate this relation. The present study aimed to fill this gap. Focused on intergroup relationships between people with different sexual orientations, it examined whether and to what extent identity processes-i.e., sexual identity commitment and exploration-mediated the relationship between online intergroup contact and perception of mediated and vicarious sexual online discrimination on Facebook. Data was collected with a sample of 357 Facebook users $\left(M_{\text {age }}=26.07, S D=8.37\right.$; females: 64.9\%, males: $35.1 \%$ ) who completed an online questionnaire. A full Structural Equation Modeling was tested. Results showed that: (a) Online contact was positively associated with perceived online sexual discrimination; (b) online contact was positively associated with identity exploration but not commitment; (c) exploration—but not commitment-was positively associated with perceived online sexual discrimination; (d) sexual identity exploration-but not commitment-mediated the relationship between online contact and perception of sexual discrimination, increasing the positive effect of contact on perceived discrimination. Limitations and directions for future research were discussed.
\end{abstract}

Keywords: e-contact; sexual identity; online sexual discrimination; Facebook

\section{Introduction}

The Contact Hypothesis (Allport 1954) has been defined as one of the most successful ideas in the history of social psychology to reduce prejudice (Brown 2000). Allport defined four optimal conditions through which intergroup contact could reduce prejudice-i.e., equal status, common goals, cooperation and authorities' support-, and the most relevant meta-analysis in the field (Pettigrew and Tropp 2000) confirmed the positive effect of contact in promoting intergroup dialogue. Since the contact hypothesis was proposed, empirical researches tested the relationship between contact and stereotypes, prejudice and discrimination reduction towards different target groups (i.e., sexual orientation, ethnicity, religion, political orientation), as well as in different contexts (i.e., countries, workplaces, etc.). More recently, given the increasing web penetration rate (e.g., InternetWorldStats.com 2020), authors (e.g., Amichai-Hamburger and Furnham 2007; White and Abu-Rayya 2012) applied contact hypothesis in the online world, aiming to understand whether and to what extent Internet could facilitate intergroup dialogue, and what specific internet features and processes could be helpful to reduce prejudice. As a recent meta-analysis showed (Imperato et al. 2020), online contact moderately reduced prejudice towards an outgroup, in line with literature concerning offline contact (e.g., Pettigrew and Tropp 2006). 
Nevertheless, the effect of online intergroup contact was highly variable and far from being explained by the characteristics of samples, studies, types of virtual context and types of contact analyzed by the studies. Thus, further studies are needed to understand the extent of the effects of online contact. For example, studies aimed to analyze how-i.e., through which processes-contact facilitates the reduction of negative attitudes towards an outgroup. This study followed this direction of research. The aim is to analyze whether and to what extent identity processes could mediate the relationship between contact and perception of sexual discrimination on Facebook.

\subsection{Online Contact, Identity Processes, and Prejudice Reduction}

Internet can foster even more intimate relationships than face-to-face communication (Walther 2011), making it an excellent tool to intergroup contact. In online contact, ingroup and outgroup members have never physically met. They interact with each other via text-only synchronous chat, or additional forms of mixed-based contacts, which include Social Network Sites, or other platforms where individuals have great access to personal information about the outgroup members, such as images, videos and information about interests and relations. Some authors (e.g., Hampton et al. 2011; Rainie et al. 2012) stated that communications via social media facilitated exposure to a variety of people and views, favoring—or hindering-prejudice reduction.

The new paradigm of online contact—also called Electronic contact or E-contact (White et al. 2015), and virtual contact (Dovidio et al. 2017)—defines online contact as "computer-mediated contact involving an engagement of Self in intergroup relations" (White and Abu-Rayya 2012). In fact, the relative anonymity afforded makes Internet a protective environment in which people choose how much they want to reveal about their own identity, and what features they want to publish online, so that reducing the risks of self-disclosure, especially for stigmatized and marginalized groups (Amichai-Hamburger and Furnham 2007). Moreover, on Internet, people have the opportunity to reduce the salience factors that denote ingroup or outgroup membership (i.e., physical characteristics), or to present themselves through multiple memberships, based on the way of contact used (i.e., text-based vs. mixed-based), in order to feel more comfortable within the interaction (White et al. 2015). As suggested by classic CMC theories, in particular the Social Identity Deindividuation Effects (SIDE; Postmes et al. 1998), anonymous and text-based intergroup interactions could increase social attraction towards an ingroup, and negative responses towards an outgroup, through the high salience of group membership (Hasler and Amichai-Hamburger 2013).

According to White et al. (2015), besides text-only based chat, Facebook or other Social Network Sites (SNS) offer additional forms of online contact. Lissitsa (2017) and Lissitsa and Kushnirovich (2018) found that frequency of online contacts on Facebook positively affected closeness to the outgroup, in line with contact hypothesis and E-contact theories. Moreover, Schwab et al. (2018) found that having outgroup members among someone's own Facebook friends list bring users to be exposed to other cultures, and that was positively associated with general outgroup attitudes. Furthermore, Imperato and Mancini (2019) showed that Facebook online intergroup contact made users more sensitive to perceive ethnic online discrimination and to act out prosocial behavior, being online contact-perceived discrimination and online contact-prosocial behavior relations mediated by commitment within the Facebook community.

In summary, some studies have shown that the relationship between online contact and prejudice can be mediated by the identity processes that are activated in an online platform such as Facebook.

\subsection{Online Intergroup Contact for LGBT Communities}

In the last years, authors interested in studying online intergroup contact increased, as well as target groups to which online contact has been applied (i.e., different ethnic groups or different religious groups). In spite of this, the meta-analysis conducted by Imperato et al. (2020) counted only 6 out of 29 studies focused on a sexual group target. Though, being a minority, intergroup relationships are extremely common among LGBT communities. In online (vs face-to-face) contexts, stigmatized 
group membership from other cues (e.g., Tabak and Zayas 2012) would be less detectable (MacInnis and Hodson 2015). MacInnis and Hodson (2015), Study 1 and Study 2 conducted two experimental studies aimed towards the examination of the outcomes of disclosing one's homosexuality earlier or later in a developing online relationship, founding more positive outcomes when gay/lesbian group membership was immediately salient. Moreover, White et al. (2019) found an overall positive online intergroup contact effect on reduced homonegative behavioral intentions, and this effect was stronger for man than for woman. Furthermore, Wu et al. (2018), starting from the discrepancy between attitude towards homosexuality in offline and online Chinese contexts, confirmed the de-stigmatizing effect of Internet towards homosexuality through contact with gay people. Kim and Wojcieszak (2018) found that online contact with an LGBT community member reduced negative attitudes toward the outgroup, making people feel less anxious or angry, so that enhancing positive emotions and minimizing negative ones. Nevertheless, there were still few studies that considered how intergroup contact can reduce prejudice towards sexual minorities. This study aims to make a contribution in this direction.

\subsection{The Present Study}

According to Hasler and Amichai-Hamburger (2013), one of the greatest challenges in studying online contact and prejudice reduction was understanding which variables could influence (i.e., mediate or moderate) this relationship, and how online contact reduced prejudice. Among variables that could be considered, identity processes, such as group identification, assumed a central and still little explored role, since the extent to which the individuals identify with his or her ingroup, appear to be the most important moderators of generalization effects (Crisp and Beck 2005).

By taking up this suggestion, this study aims to analyze whether and to what extent identity processes could mediate the relationship between online contact and perception of online sexual discrimination through a sample of Italian Facebook users. Specifically, this study took into consideration two kind of identity processes: Namely exploration and commitment to one's sexual identity. Exploration and commitment refer to well-known and widely used identity status paradigm (Marcia 1966). Based on semi-structured interviews conducted on a sample of 20 late-adolescent men, Marcia expanded Erikson (1968) ideas on identity development in different areas and in sexual identity area too, through two behavioral indicators: Exploration, consisting in the active questioning and weighing of various identity alternatives before making decisions about values, beliefs, and goals that one will pursue; commitment, referring to make a relatively firm choice in an identity domain considered important and engaging in significant activities oriented towards the implementation of that choice. Over 50 years of studies have consistently showed that there is the co-presence of exploration and commitment that guarantees psychological well-being and social adaptation (e.g., Meeus et al. 1999). This relationship has also been demonstrated with respect to the development of sexual minority (e.g., Bauermeister et al. 2010) and majority (Worthington and Mohr 2002) identity, showing that regardless of the sexual orientation with which participants identify themselves, those who were classified in the achievement identity status-i.e., with high score on both exploration and commitment-scored higher on measures of esteem and lower on measures of distress (Shepler and Perrone-McGovern 2016).

CMC studies (e.g., Turkle 1995) often considered online environments as an "identity playground" where users can explore different aspects of their identities, including their own sexual identity. From this point of view, the perception of online discrimination can be considered as part of the development of sexual identity and in particular as a type, or as a consequence, of identity exploration and commitment. Thus, in light of the literature on both the new paradigm of online contact and on identity status paradigm we expect that:

Hypothesis 1 (H1). Online intergroup contacts-i.e., contact on Facebook with people of sexual orientation other than their own-positively associated with the perception of online sexual discrimination-i.e., sexual based discrimination. 
Hypothesis 2 (H2). Online intergroup contacts positively associated with identity processes, i.e., with exploration.

Hypothesis 3 (H3). Online intergroup contacts positively associated with identity processes, i.e., with commitment.

Hypothesis 4 (H4). Exploration and commitment positively associated with perceived online sexual discrimination.

Hypothesis 5 (H5). Sexual identity exploration and commitment mediated the relationship between online contact and perception of sexual discrimination increasing the positive effect of contact on perceived discrimination.

\section{Methods}

\subsection{Study's Design and Procedure}

The present study is based on a cross-sectional data collected through an online survey administered in Qualtrics platform (www.qualtrics.com) in November 2019. To be eligible to participate in the study, participants had to be of age and to have one or more Facebook accounts. The data have been collected by 10 master degree psychology students during the participation in a research methodological course. The students did not receive any specific credits for their participation: they were instructed to follow an administration protocol which included: (a) Sending or posting the anonymous link to their e-mail, WhatsApp, Facebook and other social network contacts; (b) doing a recall to participate in the survey after 5 days from the first advice; (c) specifying the methods used to collect the data in terms of time, people or groups involved, channel used for sending or posting the anonymous link (e-mail, WhatsApp, etc.), and any comments and feedback received by participants.

Complying with the Italian ethical standards, the first page of the questionnaire contained an Informed Consent form with information about: the aim of the survey, confidentiality, anonymity and data protection. Participants gave their consent to participate in the study by clicking 'yes, I agree to participate' (or 'no') at the end of the informed consent form. Participants who did not give their consent were automatically directed to the acknowledgment page. Through a filter, participants who claimed to be under 18 years old or the ones who claimed they have not a Facebook account were led to the final thank you message placed at the end of the questionnaire.

\subsection{Participants}

A sample of 409 adult Facebook users gave their consent to participate in the survey and completed it. However, 35 participants were excluded from the data analyses: three because of missing data (they completed less than $75 \%$ of the questions), 6 did not specify their sexual orientation, and 26 identified as multivariate outliers through the Mahalanobis distance $(p<0.001)$. In the remaining sample of 374 participants, missing values on items related to each one of the three study's constructs (online contacts with sexual minorities, sexual identity processes, and online perceived discrimination) were replaced using multiple imputation with Regression Method, a method proven to be generally effective in managing missing data (see, e.g., Graham 2009). Then, 27 more multivariate outliers were identified through the Mahalanobis distance $(p<0.001)$ and excluded from data analyses.

The final sample is composed of 357 Italian participants (125 males, $35.1 \%$ and 231 females, $64.9 \%$, 1 missing) aged between 18 and 69 years $(M=26.07, S D=8.37)$. Participants' sexual orientation has been measured through a 5-point-scale: exclusively heterosexual $(82.6 \%, \mathrm{n}=295)$, predominantly heterosexual $(10.9 \%, n=39)$, bisexual $(1.4 \%, n=5)$, predominantly homosexual $(2.5 \%, n=9)$, exclusively homosexual $(1.4 \%, \mathrm{n}=5)$. The majority $(207,58.0 \%)$ were students, $117(32.8 \%)$ workers, $23(6.4 \%)$ unemployed, and 8 (2.2\%) were student workers or trainees. 
Regarding their experience with Facebook, participants declared to have an average of 50 to 100 and more contacts, and to spend on Facebook an average of 10 to 30 and more minutes per days.

\subsection{Measures}

Participants completed an anonymous questionnaire composed of different scales. They completed scales related to their experience with Facebook, specifically on their Facebook use, their online contacts with people who do not have their sexual orientation, and on their perception of sexual online discrimination; then, they completed a scale based on identity status paradigm (Marcia 1966) measuring their sexual identity.

Facebook use. It was measured through the Facebook Intensity Scale (FIS; Ellison et al. 2007). The scale included two self-report assessment on number of Facebook "friends" and on the amount of time spent on Facebook on a typical day, and six attitudinal items assessed on a 5 point Likert-type scale ( 1 = strongly disagree, 5 = strongly agree) measuring emotional connectedness to Facebook and its integration into individuals' daily activities (e.g., "I feel I am part of the Facebook community", "Facebook is part of my everyday activity"; $\alpha=0.78)$.

Online (quantity/quality) intergroup contacts. Participants were asked how often (from $1=$ never to 5 = always), through Facebook, they came into contact with people who didn't have their sexual orientation (quantity of online contacts). After, participants completed a scale measuring the quality of these contacts. This scale is built ad hoc and it is composed of 5 items assessed on a 5-point Likert-type scale ( 1 = never, 5 = always; e.g., "How often do you feel helped on Facebook by people that are not of your same sexual orientation?"; $\alpha=0.92)$.

Online Discrimination. It was measured through the Perceived Online Sexual Discrimination scale (POSDS). POSDS is an adaptation of Perceived Online Racism Scale (PORS, Keum and Miller 2017) proposed in its short version by Imperato and Mancini (2019). POSDS is composed of 12 items on a 5-point Likert-type scale (from $1=$ never to 5 = always) measuring Personal discrimination (4 items, e.g., "Have you received on Facebook negative comments about your sexual orientation?"), Mediated discrimination (4 items, e.g., "Did you read on Facebook a news or post about inequalities in access to the health system for sexual minorities?"), and Vicarious discrimination (4 items, e.g., "Did you read on Facebook in posts that became viral in which your sexual orientation was denigrated?"). Since the sample was composed largely of heterosexual individuals, i.e., the sexual majority, only the scales concerning Mediated $(\alpha=0.75)$ and Vicarious $(\alpha=0.67)$ discrimination have been considered in this study.

Sexual identity. It was measured through the Multigroup Sexual Identity Measure, short form (MSIM-R). MSIM-R is an adaptation to sexual orientation of the Multigroup Ethnic Identity Measure (MEIM-R; Phinney and Ong 2007). The MSIM-R is composed of six items on a 5-point Likert type scale ( 1 = strongly disagree, 5 = strongly agree) measuring sexual orientation Exploration ( 3 items, e.g., "I have often done things that will help me understand my sexual orientation better", $\alpha=0.75)$ and sexual orientation Commitment (3 items, e.g., "I have a strong sense of belonging to ward people with my same sexual orientation" $\alpha=0.63)$.

\subsection{Data Analyses}

For all scales, the related items were averaged to create a composite score: higher scores indicated higher levels of the measured constructs. Preliminary analyses, including means and bivariate correlations among design measures and among design measures and gender (female $=1$ ), age, sexual orientation, and FIS are presented first. Analyses of the structural equation models follow.

\section{Results}

\subsection{Descriptive Analyses}

Descriptive statistics and zero-order correlations are presented in Table 1. 
On average, participants declared that they "sometimes" came into contact with people who didn't have their same sexual orientation and that on average they have "sometimes" felt helped, supported, appreciated or have established friendly relationships on Facebook with people who did not have the same sexual orientation. However, they also stated that they "rarely" perceived forms of sexual discrimination on Facebook and, even more rarely, forms of vicarious discrimination. As to sexual identity, participants reported average scores very close to the theoretical median of the scale, more shifted towards the pole of the agreement for the dimension of commitment and towards the pole of disagreement for the dimension of exploration.

With the exception of the correlations between online contacts $(C)$ and identity commitment (COM), and between identity commitment (COM) and the two discrimination forms (DM and DV), design measures were significantly and positively correlated with one another.

Table 1. Mean and standard deviation and zero-order correlations of considered measures $(\mathrm{n}=357)$.

\begin{tabular}{|c|c|c|c|c|c|c|c|c|c|c|c|}
\hline & $M$ & $S D$ & $\begin{array}{c}\text { Cronbach's } \\
\alpha\end{array}$ & 1 & 2 & 3 & 4 & 5 & 6 & 7 & 8 \\
\hline 1. Gender $(1=\mathrm{F})$ & 1.65 & 0.48 & - & 1 & & & & & & & \\
\hline 3. Sexual orientation (SO) & 1.31 & 0.84 & - & -0.01 & -0.07 & 1 & & & & & \\
\hline 4. Facebook use (FIS) & 2.78 & 0.72 & 0.78 & 0.08 & $0.13 *$ & -0.06 & 1 & & & & \\
\hline 5. Intergroup contacts $(C)$ & 2.71 & 0.99 & 0.89 & $0.27^{* *}$ & 0.05 & $0.14^{* *}$ & $0.23 * *$ & 1 & & & \\
\hline 6. Identity exploration (EXPL) & 2.95 & 0.94 & 0.75 & 0.06 & -0.08 & $0.37^{* *}$ & $0.11 *$ & $0.18 * *$ & 1 & & \\
\hline 9. Vicarious discrimination (DV) & 1.73 & 0.63 & 0.68 & $0.12 *$ & $-0.14^{* *}$ & $0.28 * *$ & 0.06 & $0.18 * *$ & $0.24 * *$ & 0.08 & $0.61 * *$ \\
\hline
\end{tabular}

Gender (female $=1$ ) was weakly and positively related to perceived discrimination (both mediate and vicarious) and appreciably and positively related to online intergroup contact. Instead, gender was uncorrelated to both identity processes (exploration and commitment). Facebook use (FIS) slightly increased with age, while age was weakly and negatively correlated to perceived discrimination (both mediate and vicarious). With the exception of identity commitment, sexual orientation (SO) positively correlated with online intergroup contacts, identity exploration, and perceived discriminations (both mediated and vicarious). Finally, Facebook use (FIS) was appreciably and positively related to online intergroup contact and weakly and positively related to identity exploration.

\subsection{Testing the Model}

In order to test the study's hypothesis, a full model was performed using M-PLUS, v. 8.1 statistical package (Muthén et al. 2017). All variables of the model were latent variables and the full model was constructed considering online intergroup contact as exogenous variable, and identity exploration, identity commitment, mediated and vicarious discrimination as endogenous variables; identity exploration, commitment, and perceived mediated and vicarious discrimination were allowed to co-vary. Moreover, an inspection of modification indices suggested two correlation between items of similar content and belonging to the same construct: Specifically, two items of contact scale and residuals of two items of vicarious discrimination, which residuals were allowed to covary. Maximum likelihood estimation was performed. Multiple indices of Comparative fit index (CFI), Tucker Lewis index (TLI), Root mean square error of approximation (RMSEA) and Standardized root mean square residual (SMSR) were used to assess the fit of the models presented in this study. Usually, CFI and TLI values greater than 0.95 as well as SMSR value lower than 0.05 indicate an excellent model fit; values of CFI higher than 0.90 and of RMSEA values smaller than 0.08 are indicative of an acceptable fit (Byrne 2012; Kenny 2015).

The results of model 1 are reported in Figure 1. Coefficients are presented in Table 2. As predicted by Hypothesis 1, online intergroup contact was positively associated with both mediated and vicarious discrimination. Moreover, as predicted (H2), online intergroup contact positively associated with 
participants' identity exploration. However, online contact was not significantly associated with identity commitment, thus not confirming the Hypothesis 3. Furthermore, only identity exploration and not also identity commitment was positively associated with both mediated and vicarious perceived discrimination, thus partially confirming Hypothesis 4. Lastly, results only partially supported the expected mediation hypothesis (H5): The only significant mediation was observed in identity exploration: i.e., online intergroup contact increased identity exploration that in turn increased participants' perception of both mediated and vicarious sexual discrimination.

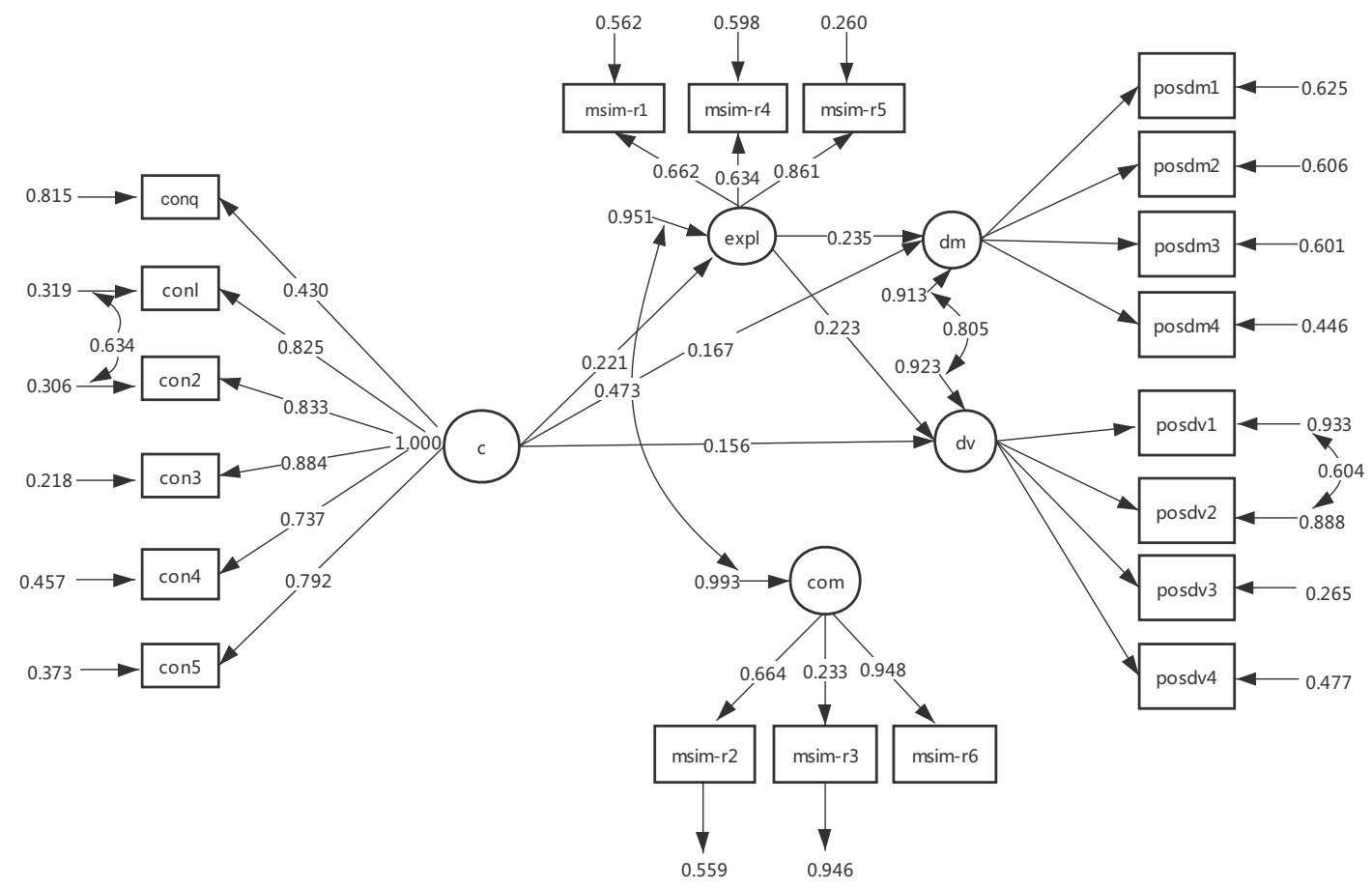

Figure 1. Predicted model.

The full model showed an acceptable fit (Byrne 2012; Kenny 2015), $\chi^{2}(158)=325.49, p<0.001$, $\mathrm{CFI}=0.95, \mathrm{TLI}=0.93, \mathrm{RMSEA}=0.06, p=0.18,90 \% \mathrm{CI}[0.046,0.063], \mathrm{SRMR}=0.060$. The model explained the $8.7 \%$ of variance for mediated discrimination and the $7.7 \%$ for vicarious discrimination.

Taking into consideration the strength of bivariate correlations (Table 1), sexual orientation was introduced as a control variable, as suggested by Muthens and Muthens' help forum (2007). Sexual orientation significantly correlated with online contact $(b=0.15, S E=0.05, t=2.84, p<0.01,95 \% \mathrm{CI}$ $[0.05,0.26])$ and with identity exploration $(b=0.37, S E=0.05, t=6.98, p<0.001,95 \%$ CI $[0.27,0.48])$ only. The full model showed a lower fit that the model without the covariate (Byrne 2012; Kenny 2015), $\chi^{2}(173)=395.28, p<0.001, \mathrm{CFI}=0.93, \mathrm{TLI}=0.91, \mathrm{RMSEA}=0.06, p=0.018,90 \% \mathrm{CI}[0.052,0.068]$, $\mathrm{SRMR}=0.066$. Results clearly showed paths very similar to that reported for the model 1 , thus confirming that online contact associated with identity exploration $(b=0.16, S E=0.06, t=2.85, p<0.01$, $95 \%$ CI $[0.05,0.28] ; \mathrm{H} 2)$, identity exploration associated with both mediated $(b=0.22, S E=0.09, t=2.41$, $p<0.051,95 \%$ CI $[0.04,0.39])$ and vicarious discrimination $(b=0.20, S E=0.09, t=2.30, p<0.05,95 \%$ CI [0.03, 0.37]; H4), online contact associated with both mediated $(b=0.16, S E=0.06, t=2.48, p<0.05$, $95 \%$ CI $[0.03,0.29])$ and vicarious discrimination $(b=0.15, S E=0.06, t=2.38 p<005,95 \%$ CI [0.03, 0.27]; H1), being indirect effect of exploration lower than in the Model 1 and not statistically significant (respectively $b=0.04$ and $b=0.03$ for mediate and vicarious discrimination). 
Table 2. Standardized estimates of direct and indirect effects of the tested model $(n=357)$.

\begin{tabular}{|c|c|c|c|c|}
\hline & $B$ & $S E$ & $Z$ & $95 \% \mathrm{CI}$ \\
\hline \multicolumn{5}{|l|}{ DM on } \\
\hline COM & -0.101 & 0.074 & -1.362 & {$[-0.246,0.044]$} \\
\hline EXPL & 0.235 & 0.080 & $2.938^{* *}$ & {$[0.078,0.392]$} \\
\hline C & 0.167 & 0.064 & $2.589 * *$ & {$[0.041,0.293]$} \\
\hline \multicolumn{5}{|l|}{ DV on } \\
\hline $\mathrm{COM}$ & -0.111 & 0.072 & -1.544 & {$[-0.252,0.030]$} \\
\hline EXPL & 0.223 & 0.078 & $2.856^{* *}$ & {$[0.070,0.376]$} \\
\hline C & 0.156 & 0.063 & $2.480 *$ & {$[0.033,0.279]$} \\
\hline \multicolumn{5}{|l|}{ IMP on } \\
\hline C & 0.043 & 0.059 & 0.724 & {$[-0.073,0.159]$} \\
\hline \multicolumn{5}{|l|}{ EXPL on } \\
\hline C & 0.221 & 0.060 & $3.704^{* * *}$ & {$[0.104,0.338]$} \\
\hline \multicolumn{5}{|l|}{ EXPL with } \\
\hline $\mathrm{COM}$ & 0.473 & 0.056 & $8.432 * * *$ & {$[0.363,0.583]$} \\
\hline \multicolumn{5}{|l|}{ DV with } \\
\hline $\mathrm{DM}$ & 0.805 & 0.041 & $19.584^{* * *}$ & {$[0.724,0.885]$} \\
\hline \multicolumn{5}{|l|}{ PORSV1 with } \\
\hline PORSV2 & 0.604 & 0.034 & $17.661^{* * *}$ & {$[0.537,0.671]$} \\
\hline \multicolumn{5}{|l|}{ CON1 with } \\
\hline CON2 & 0.634 & 0.039 & $16.057^{* * *}$ & {$[0.557,0.712]$} \\
\hline \multicolumn{5}{|l|}{ Indirect effects } \\
\hline $\mathrm{C} \rightarrow \mathrm{COM} \rightarrow \mathrm{DM}$ & -0.004 & 0.007 & -0.635 & {$[-0.018,0.009]$} \\
\hline $\mathrm{C} \rightarrow \mathrm{EXPL} \rightarrow \mathrm{DM}$ & 0.052 & 0.023 & $2.287^{*}$ & {$[0.007,0.097]$} \\
\hline $\mathrm{C} \rightarrow \mathrm{COM} \rightarrow \mathrm{DV}$ & -0.005 & 0.007 & -0.652 & {$[-0.019,0.010]$} \\
\hline $\mathrm{C} \rightarrow \mathrm{EXPL} \rightarrow \mathrm{DV}$ & 0.049 & 0.022 & $2.249^{*}$ & {$[0.006,0.092]$} \\
\hline
\end{tabular}

${ }^{*} p<0.05 ;{ }^{* *} p<0.01 ;{ }^{* * *} p<0.001$.

\section{Discussions and Conclusions}

The present work examined the relationship between online intergroup contact and perceived online discrimination against sexual minorities on Facebook. More specifically, it has been included among the amount of studies that tried to understand the process by which online intergroup contact makes individuals more sensitive to detect discrimination. Starting from the assumption that Internet could be fertile ground for identity exploration (Turkle 1995), we investigated the role of identity processes analyses based on Marcia's paradigm (1966), considering identity commitment and exploration.

Results showed that the frequency and quality of online intergroup contact on Facebook was relatively low, in line with literature findings (e.g., Lissitsa 2017). This suggested that individuals on Facebook tend to add to their friends' list ingroup members, according to a process of homophilia (Mislove et al. 2010), highlighting the tendency in social groups of similar people to be connected together. Therefore, the potentiality of making spontaneous intergroup contact is more difficult to occur. Moreover, as stated by White and colleagues (2015) in SNSs it was up to Internet users to choose to interact with outgroup members, and to report negative contact. Despite this, Internet, and particularly SNSs, facilitated the access and the exposure to different social groups in a more engaging way and with a higher level of self-involvement than other media channels (Harwood 2010), making it necessary to explore more deeply the processes that can facilitate prejudice reduction in these contexts. Results showed that, when it occurred, online intergroup contact on Facebook bring people to be exposed to different outgroups, and they turn to be more sensitive to detect online sexual mediated and vicarious discrimination. Partially confirming our hypothesis, results suggested that exploration, but not commitment, significantly mediate this relation. In other words, when people online interact with an outgroup member on Facebook, they tend to question more who they are rather than confirming their commitment to the ingroup. Our results suggested that online intergroup contact 
had the potential to stimulate active questioning about their own sexual identity, so that looking for alternatives, but not to stimulate a relative strong stance and the engagement in actions related to one's identity choice. Analyzing the participants' sexual orientation role, results showed that relationship among variables remained. In other words, the central role of identity exploration was confirmed, regardless of the belonging to the majority (i.e., heterosexual) or minority (i.e., LGBT community) group. This result gave even more strength to the model, suggesting that regardless of the group to which one belongs, online intergroup contact favored a questioning process, which circularly makes people more attentive to detect sexual discrimination.

To the best of our knowledge, this is the first study that explore the role of identity processes in online intergroup contact and discrimination. These results could pave the way for a relatively new and deeper comprehension of identity processes involved in intergroup contact in online contexts. Despite this, the present study has some limitations. First, the correlational nature of the research design should prevent researchers from inferring causal relationships among the considered variables. Second, our results can be affected by common method biases, which can limit the generalizability of the findings (Podsakoff et al. 2003). However, the study used a relatively large sample of SNSs users; this contributed to increase the robustness and the generalizability of results. Moreover, there is a need for further evidence on the mediating role of the Self, also considering group targets other than sexual minority ones. Further studies could also analyze the Self in online dialogue based on different theoretical frameworks, which allows to take into account the inclusion of the other outgroup member in the Self online (i.e., IOS; Aron et al. 1991), or self-positioning involved in the dialogue that occurs between groups online (i.e., Dialogical Self Theory; Hermans and Hermans-Konopka 2010).

Author Contributions: All authors (T.M., C.I.) contributed equally to this paper. All authors have read and agreed to the published version of the manuscript.

Funding: This research received no external funding.

Conflicts of Interest: The authors declare no conflict of interests.

\section{References}

Allport, Gordon Willard. 1954. The Nature of Prejudice. Reading: Addison-Wesley.

Amichai-Hamburger, Yair, and Adrian Furnham. 2007. The positive net. Computers in Human Behavior 23: $1033-45$. [CrossRef]

Aron, Arthur, Elaine N. Aron, Michael Tudor, and Greg Nelson. 1991. Close relationships as including other in the self. Journal of Personality and Social Psychology 60: 241. [CrossRef]

Bauermeister, José A., Michelle Marie Johns, Theo G. M. Sandfort, Anna Eisenberg, Arnold H. Grossman, and Anthony R. D'Augelli. 2010. Relationship trajectories and psychological well-being among sexual minority youth. Journal of Youth and Adolescence 39: 1148-63. [CrossRef] [PubMed]

Brown, Rupert. 2000. Group Processes: Dynamics within and between Groups, 2nd ed. Cambridge: Blackwell.

Byrne, Barbara M. 2012. A Primer of LISREL: Basic Applications and Programming for Confirmatory Factor Analytic Models. New York: Springer Science \& Business Media.

Crisp, Richard J., and Sarah R. Beck. 2005. Reducing intergroup bias: The moderating role of ingroup identification. Group Processes E Intergroup Relations 8: 173-85.

Dovidio, John F., Angelika Love, Fabian M. H. Schellhaas, and Miles Hewstone. 2017. Reducing intergroup bias through intergroup contact: Twenty years of progress and future directions. Group Processes E Intergroup Relations 20: 606-20.

Ellison, Nicole B., Charles Steinfield, and Cliff Lampe. 2007. The benefits of Facebook "friends:" Social capital and college students' use of online social network sites. Journal of Computer-Mediated Communication 12: 1143-68. [CrossRef]

Erikson, Erik H. 1968. Identity: Youth and Crisis (No. 7). New York: WW Norton \& Company.

Graham, John W. 2009. Missing data analysis: Making it work in the real world. Annual Review of Psychology 60: 549-76. [CrossRef] 
Hampton, Keith N., Lauren Sessions Goulet, Lee Rainie, and Kristen Purcell. 2011. Social Networking Sites and Our Lives. Washington, DC: Pew Internet \& American Life Project, vol. 1.

Harwood, Jake. 2010. The contact space: A novel framework for intergroup contact research. Journal of Language and Social Psychology 29: 147-77. [CrossRef]

Hasler, Béatrice S., and Yair Amichai-Hamburger. 2013. Online Intergroup Contact. Oxford: Oxford University Press.

Hermans, Hubert, and Agnieszka Hermans-Konopka. 2010. Dialogical Self Theory: Positioning and Counter-Positioning in a Globalizing Society. Cambridge: Cambridge University Press.

Imperato, Chiara, and Tiziana Mancini. 2019. Allport meets Social Network Sites: intergroup contacts and ethnic discrimination on Facebook. Paper presented at Meeting on Intergroup Communication of European Association of Social Psychology, Bologna, Italy, June 26-28.

Imperato, Chiara, Luca Caricati, Tiziana Mancini, and Yair Amichai-Hamburger. 2020. Allport meets Internet: A meta-analytical investigation on online intergroup contact and prejudice reduction. Unpublished manuscript.

InternetWorldStats.com. 2020. Internet World Stats-Usage and Population Statistics. Available online: https: //internetworldstats.com/stats.htm (accessed on 13 March 2020).

Kenny, David A. 2015. SEM: Fit (David A. Kenny). Available online: http://davidakenny.net/cm/fit.htm (accessed on 10 March 2020).

Keum, Brian TaeHyuk, and Matthew J. Miller. 2017. Racism in digital era: Development and initial validation of the Perceived Online Racism Scale (PORS v1. 0). Journal of Counseling Psychology 64: 310. [CrossRef]

Kim, Nuri, and Magdalena Wojcieszak. 2018. Intergroup contact through online comments: Effects of direct and extended contact on outgroup attitudes. Computers in Human Behavior 81: 63-72. [CrossRef]

Lissitsa, Sabina. 2017. Online political participation, online contacts with out-groups members and social distances. Asian Journal of Communication 27: 18-32. [CrossRef]

Lissitsa, Sabina, and Nonna Kushnirovich. 2018. Secondary transfer effect of positive and negative online contact between groups involved in high-intensity conflict. International Journal of Intercultural Relations 67: 71-80. [CrossRef]

MacInnis, Cara C., and Gordon Hodson. 2015. The development of online cross-group relationships among university students: Benefits of earlier (vs. later) disclosure of stigmatized group membership. Journal of Social and Personal Relationships 32: 788-809. [CrossRef]

Marcia, James E. 1966. Development and validation of ego-identity status. Journal of Personality and Social Psychology 3: 551. [CrossRef] [PubMed]

Meeus, Wim, Jurjen Iedema, Margaritha Helsen, and Wilma A. M. Vollebergh. 1999. Patterns of Adolescent Identity Development: Review of Literature and Longitudinal Analysis. Developmental Review 19: 419-61. [CrossRef]

Mislove, Alan, Bimal Viswanath, Krishna P. Gummadi, and Peter Druschel. 2010. You are who you know: inferring user profiles in online social networks. Paper presented at the Third ACM International Conference on Web Search and Data Mining, New York, NY, USA, February 3-6; pp. 251-60.

Muthén, Bengt O., Linda K. Muthén, and Tihomir Asparouhov. 2017. Regression and Mediation Analysis Using Mplus. Los Angeles: Muthén \& Muthén.

Pettigrew, Thomas F., and Linda R. Tropp. 2000. Does intergroup contact reduce prejudice? Recent meta-analytic findings. Reducing Prejudice and Discrimination 93: 114.

Pettigrew, Thomas F., and Linda R. Tropp. 2006. A meta-analytic test of intergroup contact theory. Journal of Personality and Social Psychology 90: 751-83. [CrossRef]

Phinney, Jean S., and Anthony D. Ong. 2007. Conceptualization and measurement of ethnic identity: Current status and future directions. Journal of Counseling Psychology 54: 271. [CrossRef]

Podsakoff, Philip M., Scott B. MacKenzie, Jeong-Yeon Lee, and Nathan P. Podsakoff. 2003. Common method biases in behavioral research: a critical review of the literature and recommended remedies. Journal of Applied Psychology 88: 879-903. [CrossRef]

Postmes, Tom, Russell Spears, and Martin Lea. 1998. Breaching or building social boundaries? SIDE-effects of computer-mediated communication. Communication Research 25: 689-715. [CrossRef]

Rainie, Lee, Amanda Lenhart, and Aaron Smith. 2012. The Tone of Life on Social Networking Sites. Pew Internet Report. Washington, DC: Pew Research Center. 
Schwab, Anne Katrin, Christina Sagioglou, and Tobias Greitemeyer. 2018. Getting connected: Intergroup contact on facebook. The Journal of Social Psychology 159: 344-48. [CrossRef] [PubMed]

Shepler, Dustin, and Kristin Perrone-McGovern. 2016. Differences in psychological distress and esteem based on sexual identity development. College Student Journal 50: 579-89.

Tabak, Joshua A., and Vivian Zayas. 2012. The roles of featural and configural face processing in snap judgments of sexual orientation. PLOS ONE 7: e36671. [CrossRef] [PubMed]

Turkle, Sherry. 1995. Life on the Screen: Idein the Age of the Internet. London: Weidenfeld and Nicolson.

Walther, Joseph B. 2011. Theories of computer-mediated communication and interpersonal relations. The Handbook of Interpersonal Communication 4: 443-79.

White, Fiona A., and Hisham M. Abu-Rayya. 2012. A dual identity-electronic contact (DIEC) experiment promoting short-and long-term intergroup harmony. Journal of Experimental Social Psychology 48: 597-608. [CrossRef]

White, Fiona A., Lauren J. Harvey, and Hisham M. Abu-Rayya. 2015. Improving intergroup relations in the Internet age: A critical review. Review of General Psychology 19: 129-39. [CrossRef]

White, Fiona A., Stefano Verrelli, Rachel D. Maunder, and Angus Kervinen. 2019. Using electronic contact to reduce homonegative attitudes, emotions, and behavioral intentions among heterosexual women and men: A contemporary extension of the contact hypothesis. The Journal of Sex Research 56: 1179-91. [CrossRef]

Worthington, Roger L., and Jonathan J. Mohr. 2002. Theorizing heterosexual identity development. The Counseling Psychologist 30: 491-95. [CrossRef]

Wu, Yue, Yi Mou, Yi (Jasmine) Wang, and David Atkin. 2018. Exploring the de-stigmatizing effect of social media on homosexuality in China: an interpersonal-mediated contact versus parasocial-mediated contact perspective. Asian Journal of Communication 28: 20-37. [CrossRef]

(C) 2020 by the authors. Licensee MDPI, Basel, Switzerland. This article is an open access article distributed under the terms and conditions of the Creative Commons Attribution (CC BY) license (http://creativecommons.org/licenses/by/4.0/). 